\title{
A GULF OF MEXICO MARSH RESTORATION AND PROTECTION PROJECT
}

\author{
Scott L. Douglass, ${ }^{1}$ Carl Ferraro, ${ }^{2}$ Caren R. Dixon, ${ }^{3}$ Larry Oliver and Lloyd Pitts ${ }^{4}$
}

\begin{abstract}
A \$3 million (US \$) marsh restoration and protection project was constructed in 2010 along $1.6 \mathrm{~km}$ on the northern shore of Mississippi Sound near Bayou LaBatre, Alabama to restore about 10 ha of marsh and protect another 300 ha of an extremely productive natural salt marsh estuary - Little Bay. The project restored an historic marsh peninsula with $100,000 \mathrm{~m}^{3}$ of sand pumped from a nearby dredged material disposal area; extensive vegetation plantings including over 100,000 plants; and an offshore segmented, porous breakwater consisting primarily of individual concrete units called "wave attenuation devices" or WADs. The wave transmission characteristics of these "wave attenuation devices" were measured in original laboratory wave tests for this design. The wave transmission coefficient was found to vary, $0.4<\mathrm{K}_{\mathrm{t}}<0.9$, depending on configuration, depth and wave period. In other words, the "wave attenuation devices" provide fairly minimal attenuation is some cases. The functional design of the breakwater was optimized to provide just enough wave attenuation for wetlands establishment while providing for maximum flow and ingress and egress for fishes, crabs and other species. The upper level of wave tolerance for marsh grasses following Roland and Douglass (2005) was the target level controlling the breakwater design. The Little Bay project was the largest marsh restoration/protection project in Alabama history; won several state, regional and national design awards; survived design conditions in 2011; and has functioned well to date. The success of this project suggests that the application of coastal engineering principles can improve the design of "living shoreline" projects.
\end{abstract}

Keywords: Marsh restoration, marsh protection, porous breakwater, wave attenuation devices, wave transmission, Gulf of Mexico, Alabama, Bayou LaBatre, wave tolerance, living shoreline

\section{BACKGROUND}

Salt marsh wetlands are being transformed to shallow open water habitat due to wave-driven marsh erosion as barrier islands degrade and sea levels rise along the northern Gulf of Mexico coast of the United States. These eroding areas are ecologically productive and many of the commercial and noncommercial finfish and shellfish species of the Gulf spend a critical portion of their lifespan in these salt marshes. A number of organizations are now actively pursuing construction of various alternatives with a goal of creating valuable habitat and reducing shoreline recession. These solution attempts are often called 'living shorelines" as an alternative to a traditional bulkhead or revetment. However, there has been only limited use of coastal engineering tools in the design of some of these "living shorelines" with some being pursued with an empirical, "lets-try-this-and-see-if-it-works" type approach. Some have used breakwaters which are so large and continuous that ingress and egress of fish to and from the marsh is severely limited by the breakwater structure.

This paper describes one large "living shoreline" project intended to restore and protect some of the valuable marshes of the Gulf coast. The project used applied coastal engineering techniques, including physical laboratory testing, in the design process and has won several state, regional, and national design awards from both the engineering and the conservation communities.

The Alabama Department of Conservation and Natural Resources received funding from the National Oceanographic and Atmospheric Administration in response to coastal damage in Alabama from Hurricane Katrina. As part of the Emergency Disaster Relief Program, the Post-Katrina Finfish and Shellfish Recovery: Little Bay Project was envisioned to repair hurricane damage while providing for increased habitat for shellfish and finfish, an important part of the Alabama coastal economy.

This paper discusses the site conditions, the project, the unique breakwater system designed to maximize ingress and egress of species while minimizing the breakwater structure and still achieving adequate wave attenuation, and the overall performance of the project to date.

\section{THE SITE}

The project was constructed along $1.6 \mathrm{~km}$ on the northern shore of Mississippi Sound immediately southwest of Bayou LaBatre, Alabama (see Figure 1). Erosion over the past five decades had turned

\footnotetext{
${ }^{1}$ Department of Civil Engineering, University of South Alabama, 150 Jaguar Dr., Mobile, AL, 36688, USA

2 State Lands Division - Coastal Section, Alabama Department of Conservation and Natural Resources, 31115 Five Rivers Blvd. Spanish Fort, AL 36527, USA

${ }^{3}$ South Coast Engineers, P.O. Box 72, Fairhope, AL 36533, USA

${ }^{4}$ Volkert Inc., 3809 Moffett Road, Mobile, Alabama 36618, USA
} 
over 10 ha of marsh into open shallow water, breached the peninsula which defines Little Bay (see Figures 2 and 3), and was beginning to destroy the 300+ ha Little Bay marsh - an extremely productive natural salt marsh estuary. This marsh shoreline had receded over $100 \mathrm{~m}$ since 1950 . The peninsula breach occurred in 1954. It started as a 20-m-wide breach on NOAA shoreline maps from 1954 (not shown here) and expanded to an 800-m-wide breach by 2008.

The pre-project shoreline consisted primarily of an eroding marsh scarp (see Figure 4) with typical elevations of around $+0.2 \mathrm{~m}$ (MHHW). The root-rhizome mat of the existing marsh was continually being undermined by wave action as is typical of eroding salt marshes throughout the Gulf of Mexico. The Alabama coast is a micro-tidal coast with a mean tide range of $0.4 \mathrm{~m}$.

The project site is just west, or down-drift, of the ship channel to Bayou LaBatre. The ship channel has been dredged with some of the dredged material being deposited in shallow water south of the project which became the borrow site for sand for the project. The project location is in a cove of the portion of Mississippi Sound known as Portersville Bay. The fetch distances to the south and southwest across Mississippi Sound are approximately $20 \mathrm{~km}$, that water is very shallow, and thus wave heights, $\mathrm{H}$, at the site during typical storm conditions can approach $\mathrm{H}=1 \mathrm{~m}$.



Figure 1. Little Bay, Alabama, marsh restoration and protection project location

\section{THE PROJECT}

The Little Bay project was built in 2010, cost \$3 million (US\$) to construct, and is the largest coastal marsh restoration and estuary protection project in Alabama's history. The project included the restoration of the historic marsh peninsula with sand, extensive vegetation plantings, and an offshore segmented, porous breakwater consisting primarily of individual concrete units. Figure 5 shows the entire project after construction from the air. The peninsula breach restoration was about $0.8 \mathrm{~km}$ of the total project length. The gaps in the breakwater structure are obvious as is the sand fill. The newly planted vegetation is not obvious in the photograph of Figure 5 due to the altitude of the airplane and sparseness of the young plantings. The breakwater structure was placed about $100 \mathrm{~m}$ offshore of the pre-project shoreline and extended across the historic breached peninsula area. Sand was placed south of the shoreline at a width of about $70 \mathrm{~m}$ in order to leave a significant area, about $30 \mathrm{~m}$ wide) of open water between the structures and the newly constructed marsh. It was expected that the sand would shift into tombolo formations in this area due to the wave energy passing through the gaps in the breakwater and that these variations would maximize the shallow-water habitat which can be most productive near the edge of marshes. The total length of the breakwater was about $1.6 \mathrm{~km}$ and some of the details about this unique design are discussed in a separate section of this paper below. 


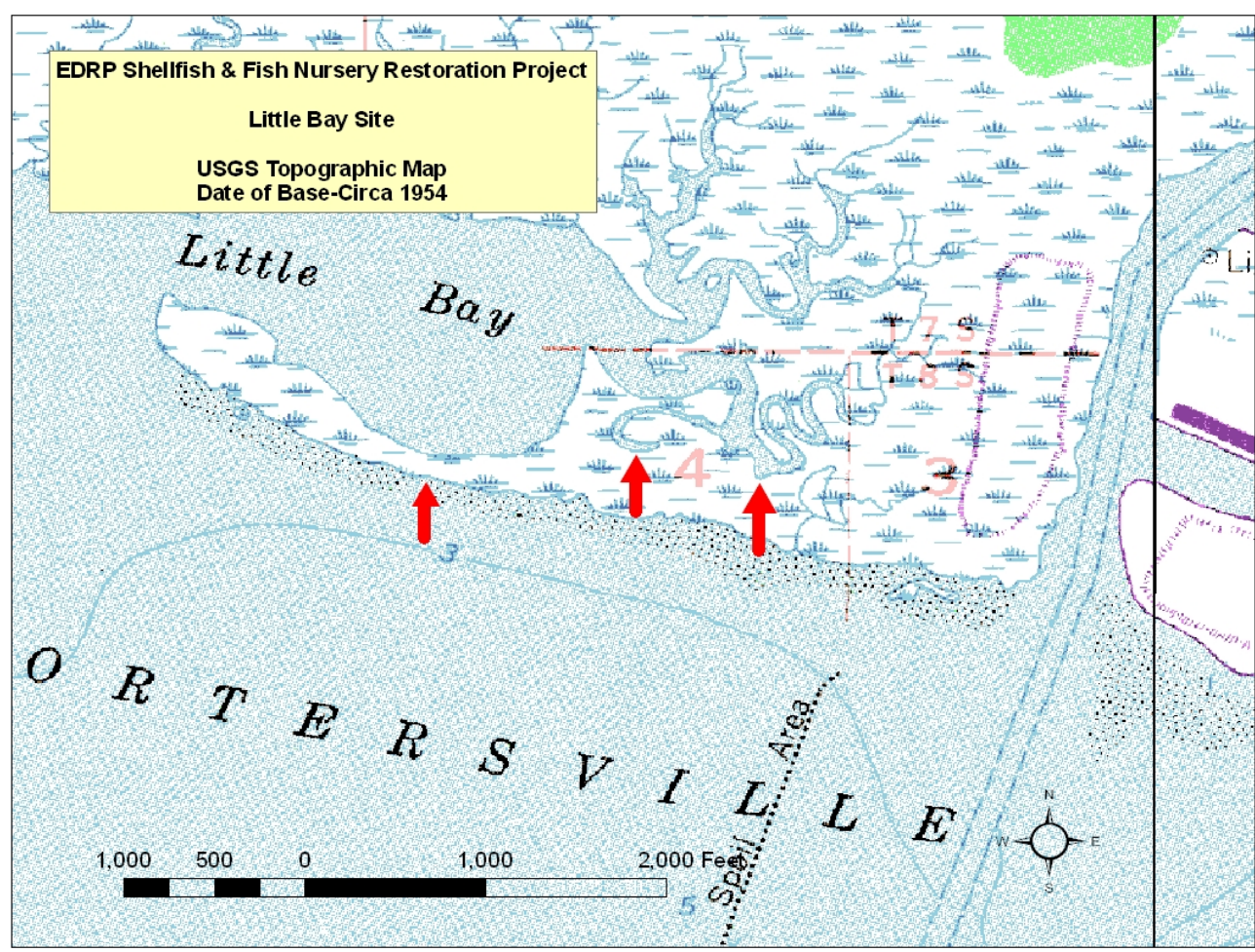

Figure 2. The Little Bay Project site shown on the navigation chart of 1954 showing the peninsula defining Little Bay not breached yet by marsh erosion. (Note: the locations of the three red arrows match those show in Figure 3.)

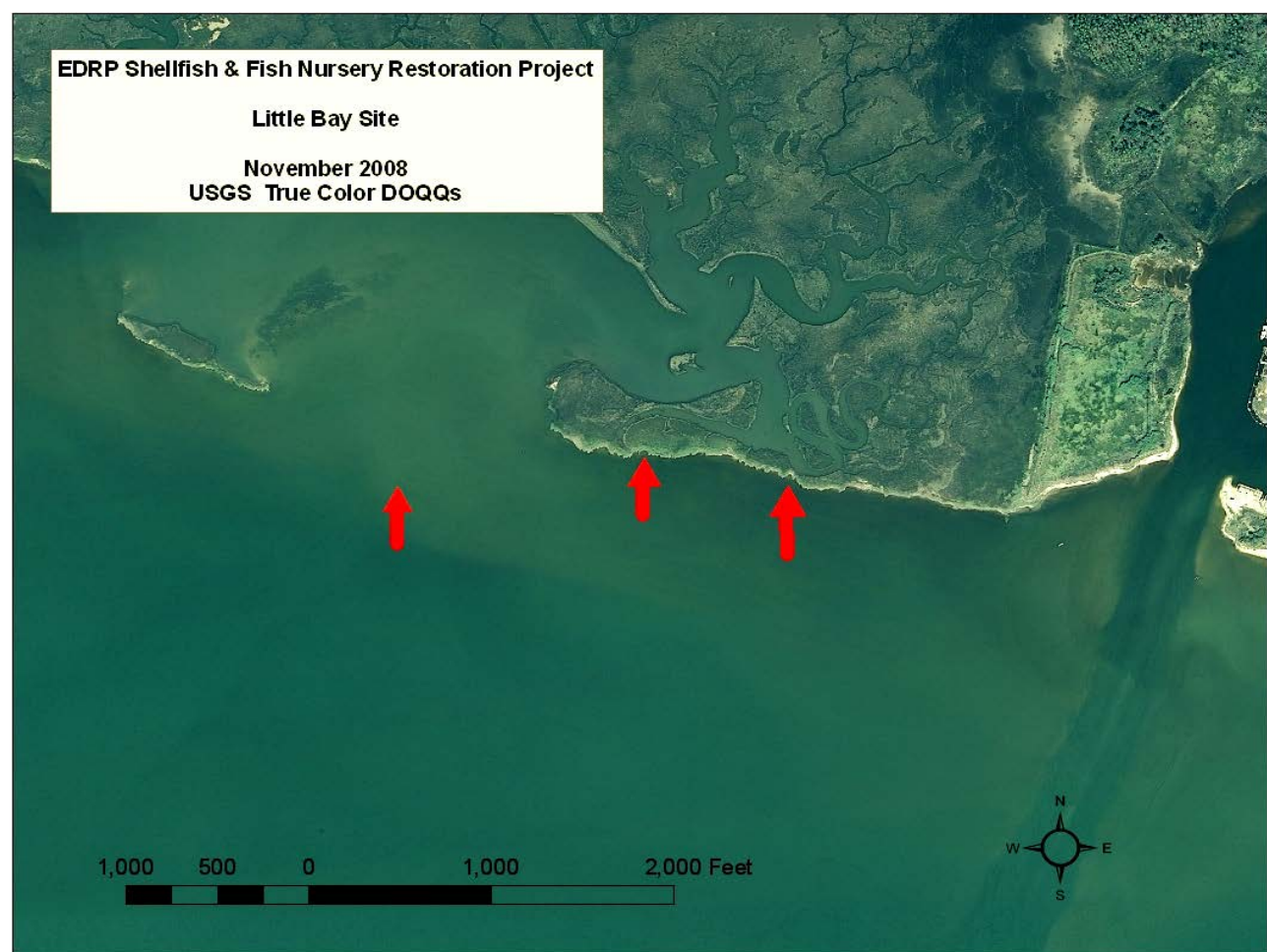

Figure 3. The Little Bay Project site in November 2008 showing the peninsula breached by marsh erosion. (Note: the locations of the three red arrows match those show in Figure 2.) 


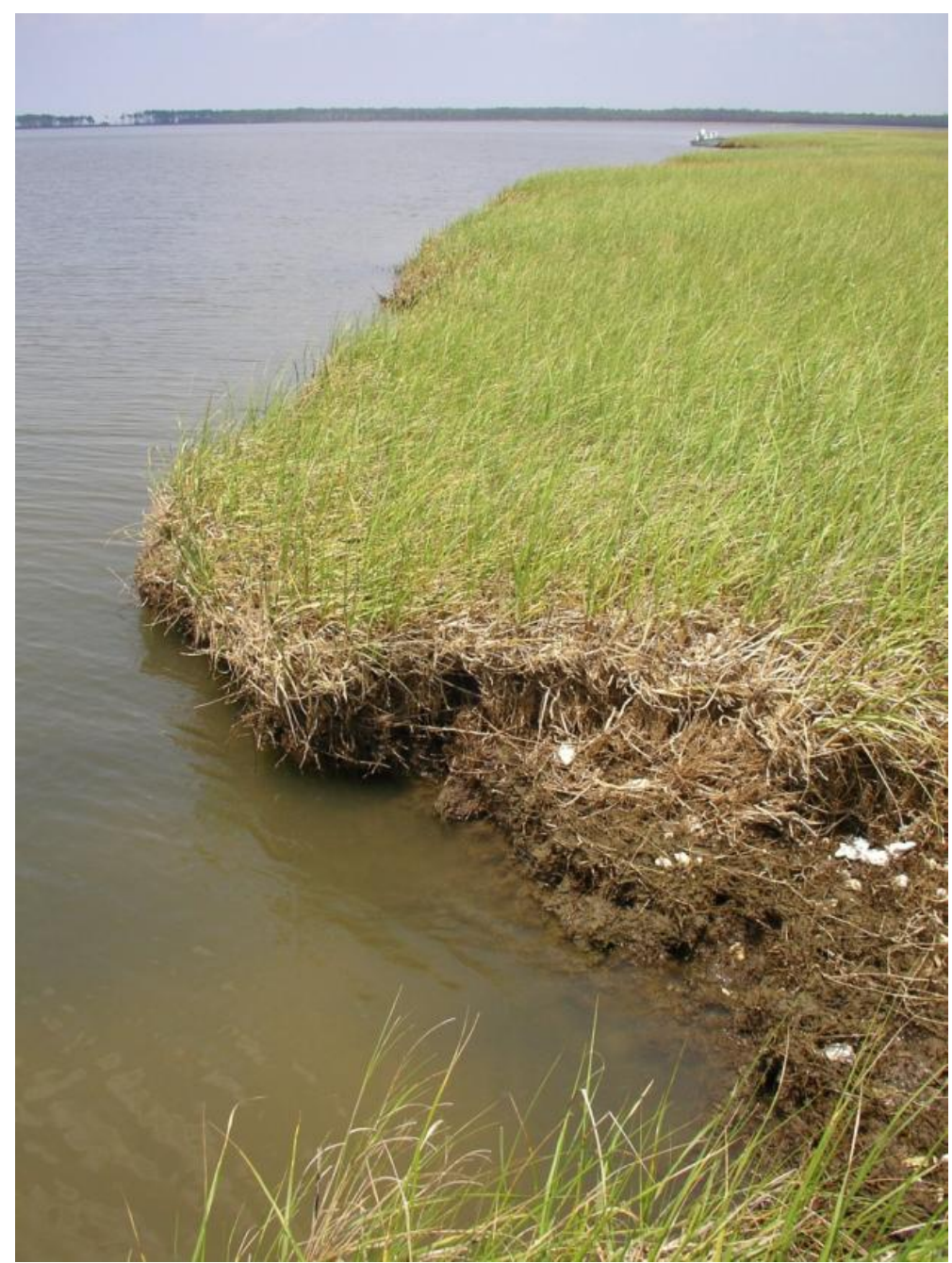

Figure 4. A photograph of a typical shoreline along the Little Bay Project site prior to construction of the 2010 project showing a vertical scarp at the shoreline.

The sand volume pumped into the lee of the breakwater was $100,000 \mathrm{~m}^{3}$. The sand was a silty sand from a nearby offshore (immediately southeast of the project) area where sands dredged from the Bayou LaBatre ship channel had previously been disposed. The contractor used a hydraulic dredge to pump the sand into the project. The 10-ha area filled had an average depth of $0.5 \mathrm{~m}$ before the project and the fill raised the elevations to around mean sea level and up to above mean high water for vegetation plantings. Post-construction ground elevation variances were part of the design template to allow for some fluctuations in grade typical of natural marshes in this area.

Over 100,000 plants were eventually planted in the Little Bay project (see Figure 6). The vegetation plantings in the marsh evolved due to cost issues and timing of funding issues. Initially about half the plants were transplanted plugs taken from the adjacent marsh. Subsequently, additional nursery raised, bare root plants were added. The planting plan was developed considering elevations found for the various wetland species in south Alabama. The plants used (and percentage of the project total) were Spartina alterniflora (80\%), Spartina patens (17\%), Juncus roemerianus (2\%), Baccharis L. (<1\%), and Distichlis spicata $(<1 \%)$. In general, the transplanted plugs had a higher level of survival. Within one year, there was, as expected in the design, both some significant sand elevation changes due to wave action and some natural colonization of grasses within the project limits.

A low breakwater, constructed of bagged oyster shells, was included on the north side of the project to keep the hydraulically pumped sediments from flowing into Little Bay where some submerged aquatic vegetation existed. Figure 7 shows that oyster shell structure and the vegetation plantings to the south. 


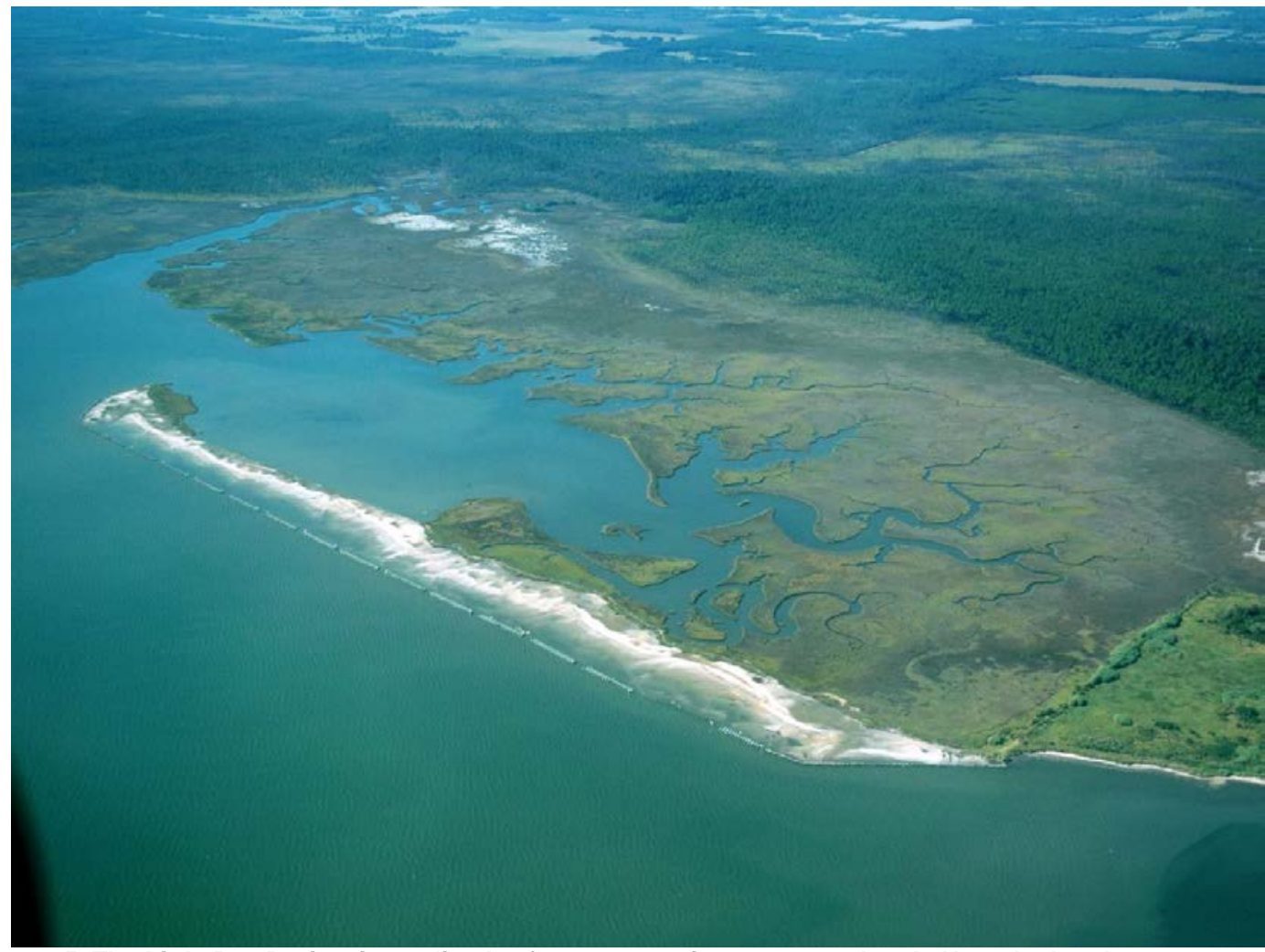

Figure 5. The Little Bay Project immediately after construction was completed. Note the breakwater structure including the gaps, the new sand, and the restoration of the peninsula defining Little Bay.

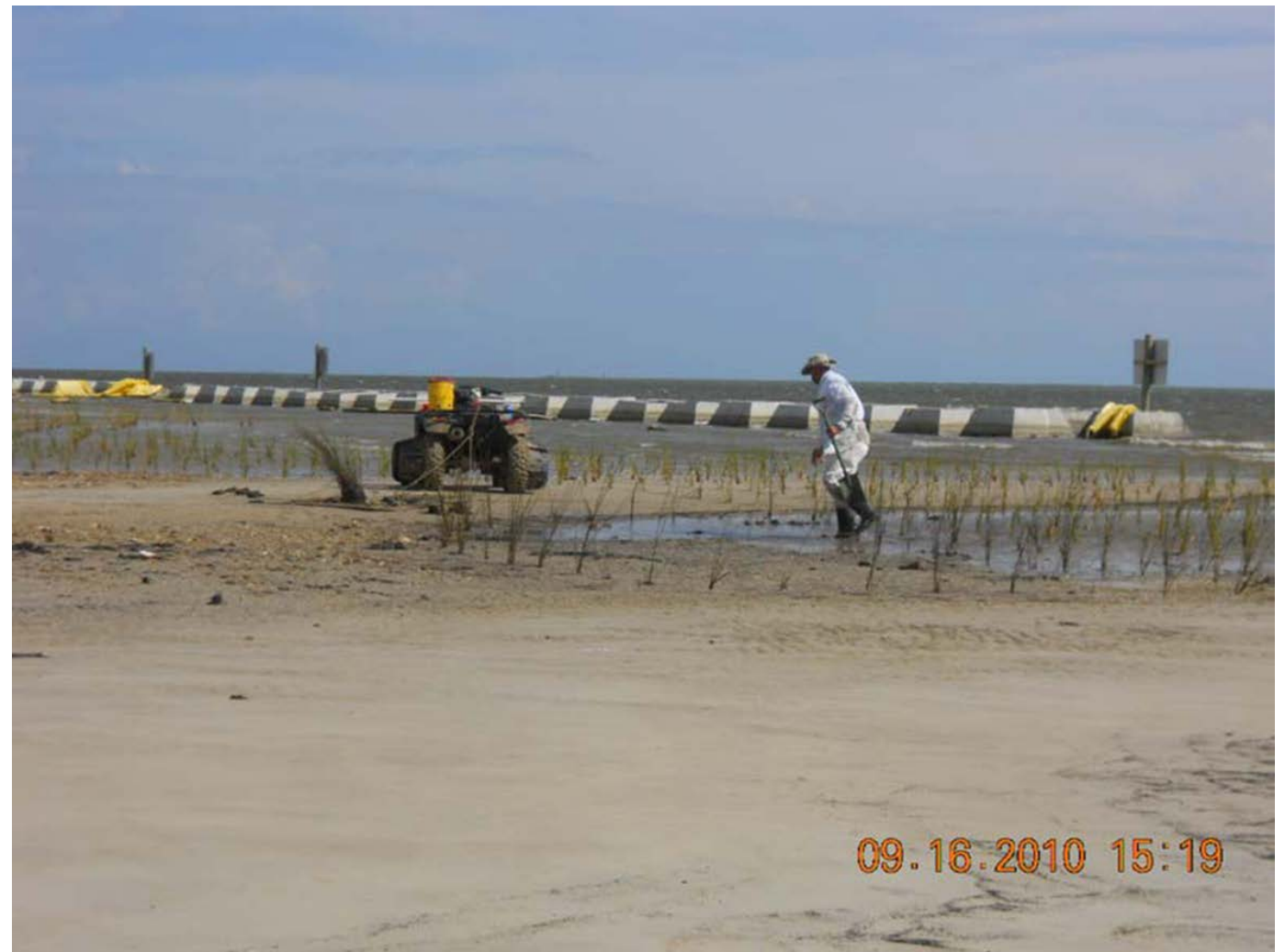

Figure 6. Planting of the S. alterniflora vegetation in the Little Bay Project by the contractor's biologist 


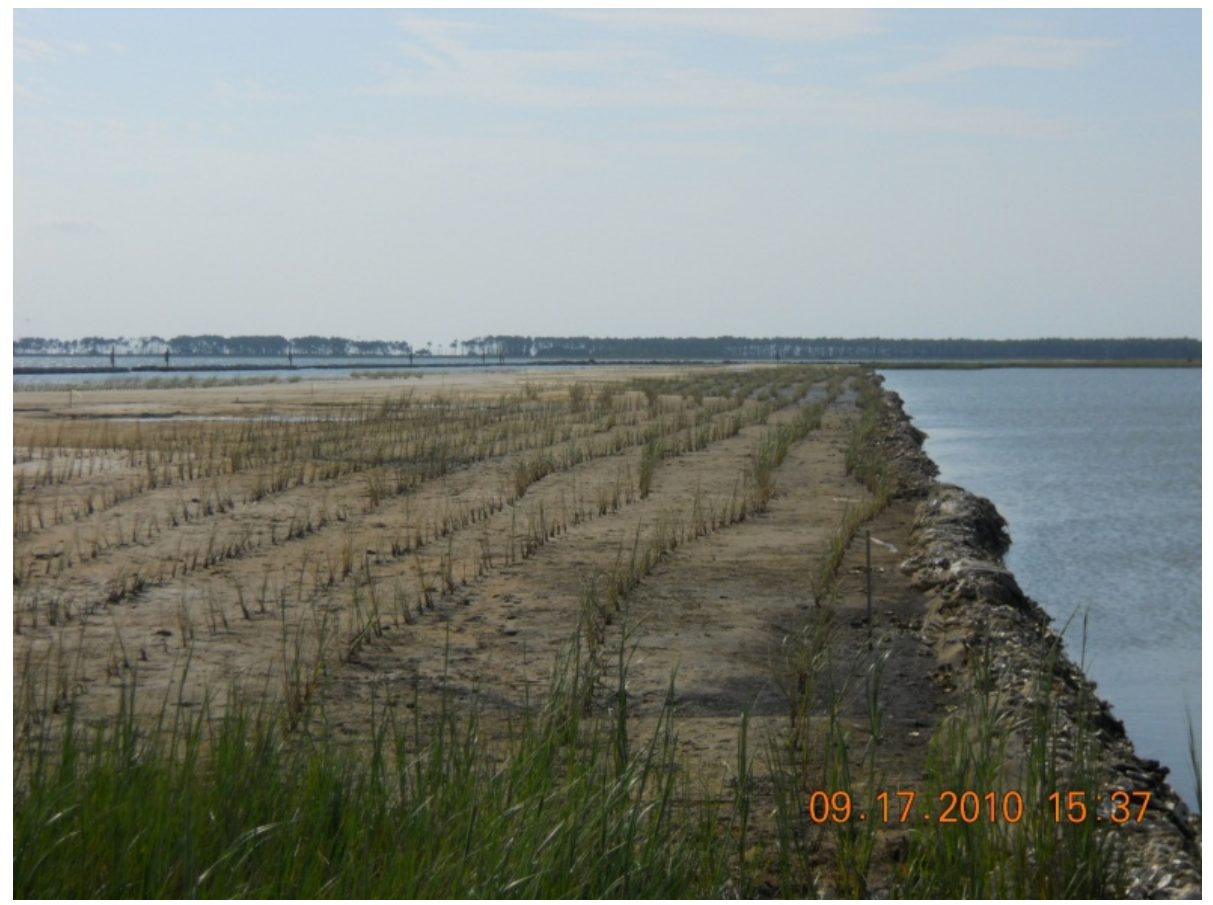

Figure 7. The bagged oyster shell breakwater used on the north side of the peninsula restoration area to hold the fill out of Little Bay.

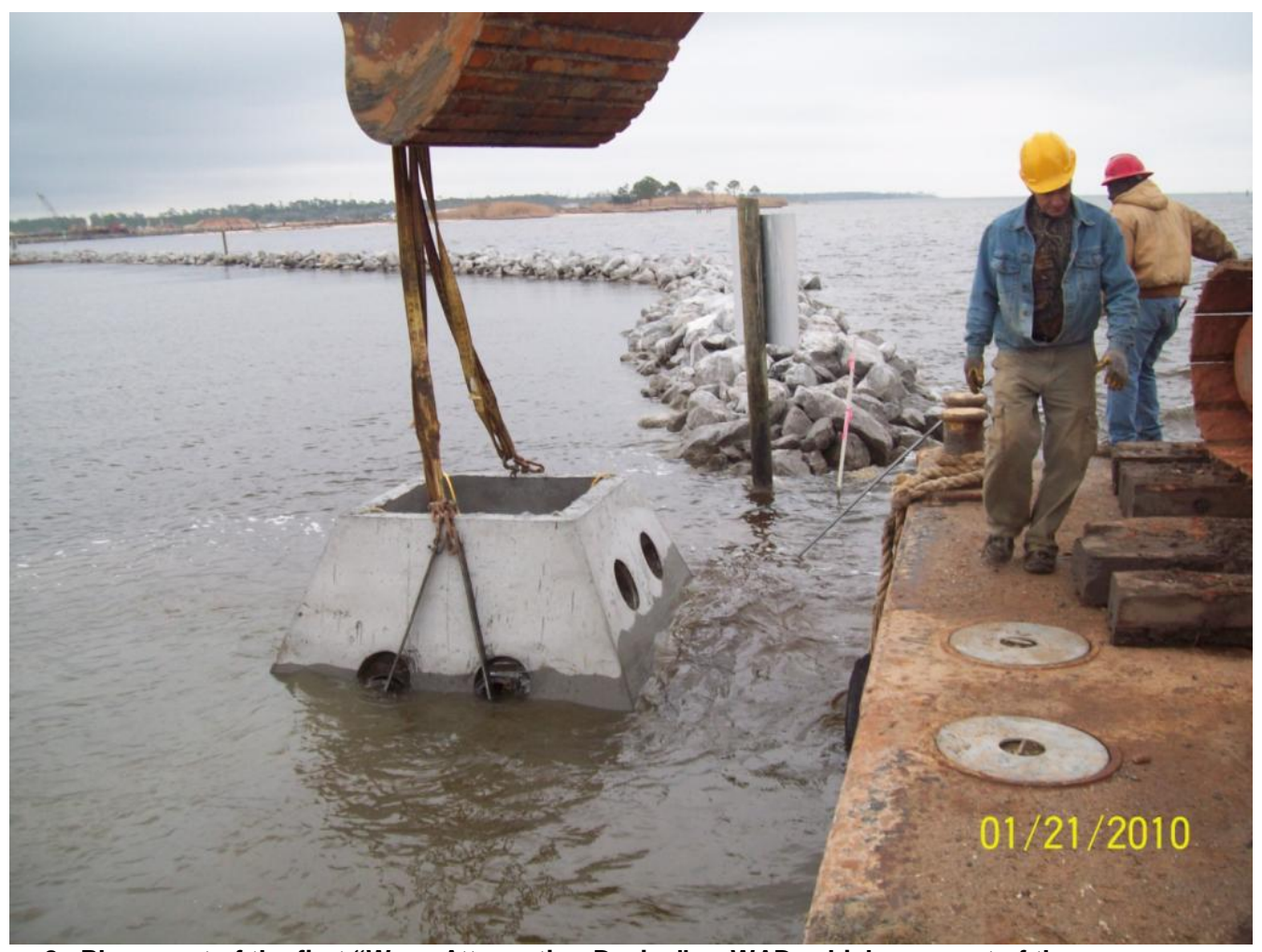

Figure 8 . Placement of the first "Wave Attenuation Device" or WAD, which was part of the porous breakwater system. In the background is the eastern end of the breakwater which was all rock. 


\section{THE BREAKWATER}

A breakwater was included in the design to reduce wave energy. This decision was based primarily on the site's erosive history but also on a quantitative analysis. Roland and Douglass (2005) quantified the level of wave tolerance for S. alterniflora in terms of the site-specific wave climate. This can be developed via wave-hindcast methods using shallow-water wave generation modeling with historic wind records. Based on that wave tolerance concept, it was determined that the level of wave energy at the site needed to be reduced in order for a mildly-sloped, mature marsh to survive. A design decision was made to establish a target level of transmitted wave height at 50-67\% of the typical storm waves based on Roland and Douglass (2005). In other words, the transmitted wave heights in the lee of the breakwater needed to be $50-67 \%$ of the incident wave heights when water levels were near the marsh surface. Thus, a rather porous breakwater could be used but it had to knock a significant fraction of the wave energy down.

Two general breakwater designs were developed at the request of the client. One, an all-rock breakwater with gaps, and, two, a breakwater consisting of so-called "Wave Attenuation Devices" or WADs. The WADs are individual concrete units of different shapes that are marketed to reduce wave energy while also providing habitat for oysters and fish. The WADs are essentially pyramidal-shaped with either triangular bottoms (3-side pyramids) or rectangular bottoms (4-sided pyramids) arranged in rows. The goal was to develop a cost-effective breakwater system which obtained the target wave sheltering while maximizing the ingress and egress paths for finfish and shellfish (crabs) as well as providing hard habitat for oysters. The selected design was a hybrid breakwater including both WADs with gaps as the primary structure and continuous rock structures at both ends. This selection was based partially on cost and partially on regulations related to oyster harvesting near a ship channel.

The WADs used in the Little Bay breakwater were 4-sided pyramids as shown in Figures 8, 9, and 10. This specific shape can be called an apex-truncated square pyramid. This general shape is a sixsided polyhedron or hexahedron. The WADs used in the Little Bay project were constructed offsite and barged to the project. The WADs were hollow and had no solid face on the bottom or the top. They were $1.8 \mathrm{~m}$ tall, $3 \mathrm{~m}$ by $3 \mathrm{~m}$ on the bottom, and $1.5 \mathrm{~m}$ by $1.5 \mathrm{~m}$ on the top. There were circular holes in all four faces of the WADs: five holes on the south face and two holes on other faces. Each WAD weighed 7.2 metric tonnes and 546 WADs were used in the overall project. No geotextile was used for foundation strength and it was expected, based on soil tests, that the WADs would settle $15 \mathrm{~cm}$ because of consolidation processes and differentially scour through time.

Figure 8 shows the placement of the first, easternmost, WAD during construction of the breakwater. The eastern end of the breakwater which is all rock, is in the background of Figure 8. The WADs were arranged as a breakwater by configuring them in two rows where one row was offset, or staggered, behind the other. Figure 10 shows the two row configuration as built from the water. This photograph is taken looking west from one of the gaps. Figure 11 shows the two row configuration with gaps from the air (before sand was placed in the lee of the breakwater). The sections of the breakwater were $61 \mathrm{~m}$ long with 12 m gaps. Each breakwater section consisted of 39 WADs with 20 in the southern row and 19 in the northern row. The wave transmission through the gaps was modeled with Goda's method (Goda 2000) with the gap width, 12-m, designed to achieve the target wave levels described 30m behind the gaps.

Initially, it was suggested by others that the WADs could be $1.4 \mathrm{~m}$ tall for this project and some WADs of that height were made available for this project. These units had previously been used in Florida as an experimental structure designed to reduce wave energy and foster the development of submerged aquatic vegetation. It had been determined that they were unsuccessful in achieving those goals and were due to be removed from that site. They were brought to the Little Bay project site prior to construction of the main project and used as a "test section" or general "proof of concept" section for WADs. Those smaller WADs were ultimately left in place as part of the project breakwater and are the barely visible portion of the breakwater near the right side of Figure 11 (and Figure 5 shows that this section became the $2^{\text {nd }}$ most eastern breakwater section).

One of the primary challenges during the design phase of the Little Bay project was a lack of information on the wave transmission characteristics of WADs. Although they were being marketed to attenuate waves, there was no available, adequate design guidance quantifying their attenuation characteristics for engineering design. Thus, some original laboratory tests were done to quantify the wave transmission coefficients for the WADs used in this study. 


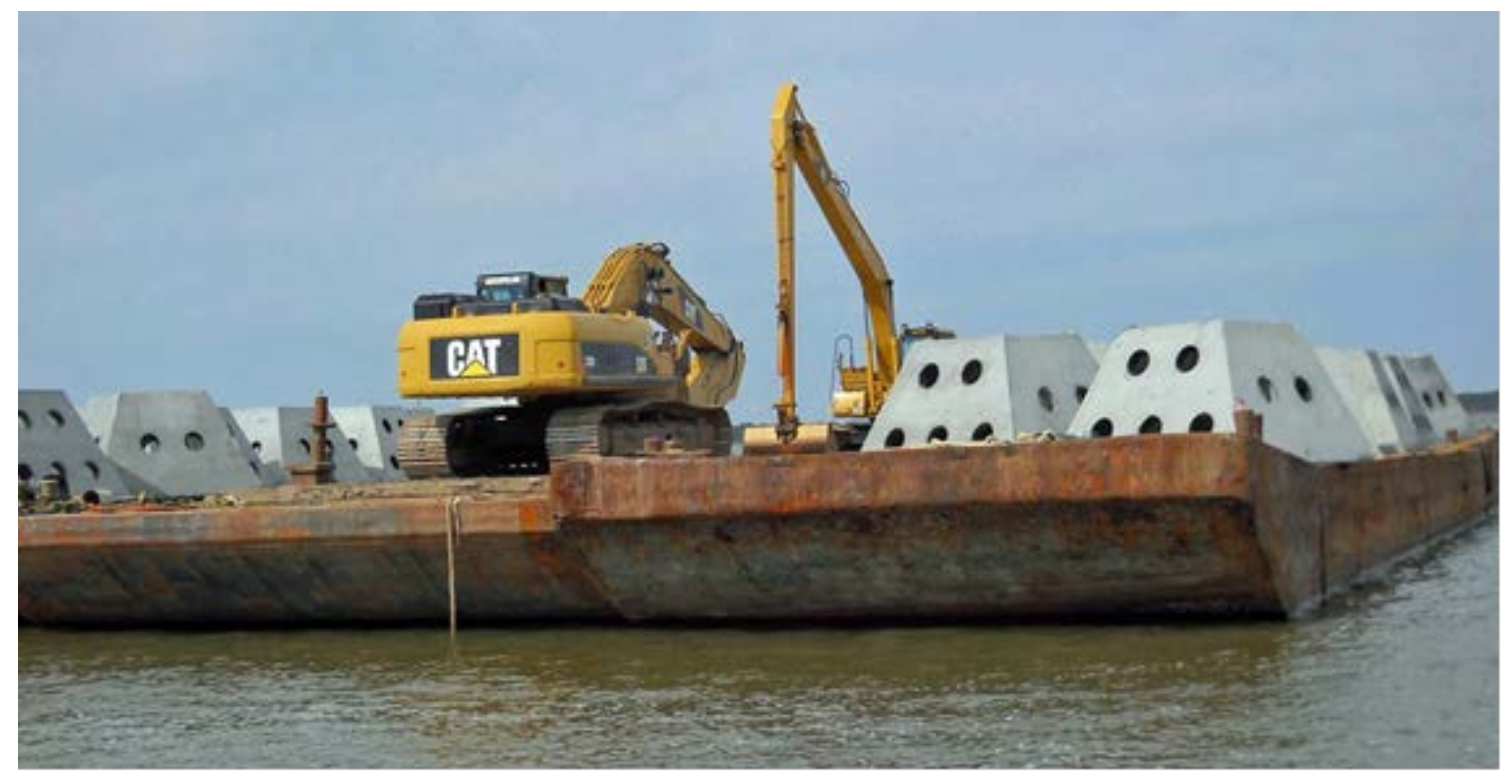

Figure 9. The "Wave Attenuation Devices," or WADs, used in the Little Bay project breakwater. The WADs used here were truncated, four-sided, pyramid-shaped concrete units with circular holes in the faces.



Figure 10. Water-level photograph of the Little Bay Project breakwater during construction before sediment pumping and vegetation planting. This photograph shows the end of one of the 61-m long breakwater sections taken from in one of the 12-m long gaps in the breakwater. 


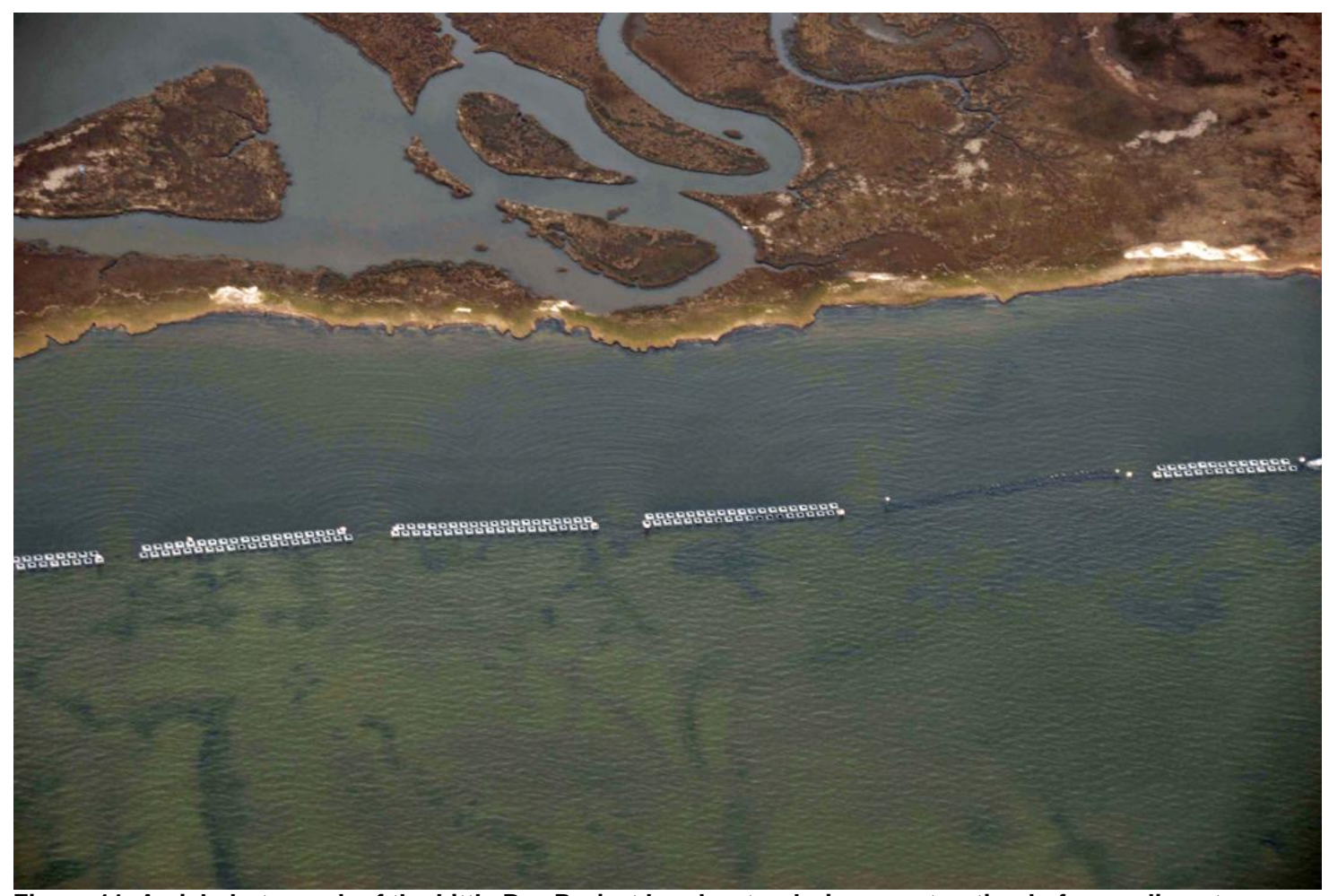

Figure 11. Aerial photograph of the Little Bay Project breakwater during construction before sediment pumping and vegetation planting. Note the two rows of WADs (so-called Wave Attenuation Devices) and the gaps between the rows of WADs.

\section{LABORATORY TESTS OF WAVE TRANSMISSION CHARACTERISTICS OF "WADS"}

One of the design alternatives considered for the breakwater at the Little Bay project, and the alternative which was ultimately selected based on cost, was the use of rows of "Wave Attenuation Devices" (WADs). These WADs are rows of perforated, individual concrete units placed to provide both habitat and reduce wave energy. Physical scale-model tests were conducted in the wave basin at the University of South Alabama to determine the wave transmission characteristics of the WADs under consideration. The results of the laboratory tests were used in design of the WAD breakwater alternative. The functional design aspects of the breakwater; height, length, gaps, spacing, location, and number of rows of WADs; were established to reduce the wave energy to the target tolerance level discussed above. These lab tests were designed specifically to provide focused data which could be used in the design at Little Bay and were not general research tests. As such, there was a relatively narrow set of test conditions.

The University of South Alabama wave basin is a rectangular, $6 \mathrm{~m}$ by $9 \mathrm{~m}$, wave basin with $0.9 \mathrm{~m}$ high walls. It has a single, 6-m wide programmable bulkhead capable of generating waves which propagate down the longer axis of the basin. Figure 12 shows the basin with the generator at the far end and one of the WAD test configurations (single row, oblique wave angle) during these tests. Monochromatic waves were used for these tests.

The structures used were 1:5 (model:prototype) scale models of WADs provided by a WAD manufacturer. The scale is essentially a nominal scale selected based on a preliminary design for the Little Bay project for prototype water depths about $1 \mathrm{~m}$ and prototype structure heights of $1.5 \mathrm{~m}$. The scale model structures tested had a height of $0.30 \mathrm{~m}$. Figure 13 shows a photograph of the structures tested. These shapes differed slightly from those used in the prototype as these had a top face in the lab with rocks embedded in the top. This feature was not specified in the prototype design. The base size of the test WADs was $0.61 \mathrm{~m}$ square and the slope up from the base made an internal angle of $58^{\circ}$ with the bottom. The lengths discussed are nominal lengths as there was some variability in the seven units used in these tests (up to $0.1 \mathrm{~m}$ of bottom and side length variability). This variability was likely due to the construction methodology. The model structures were hollow with no bottom surface and a concrete wall thickness of about $5 \mathrm{~cm}$. There were $6.3 \mathrm{~cm}$ diameter holes in each of the five upper surfaces. The 
top surface had one hole, three of the sloped side surfaces had 2 holes, and one sloped side surface had 5 holes. The 5-hole side was set facing the bulkhead, i.e. facing seaward, for these tests.

Several different configurations of the individual units were tested with the waves approaching head on (wave crests parallel to the main axis of alignment of the breakwater units):

- One row of units,

-Two rows of units close (essentially touching at the base) together and staggered.

-Two rows of units spaced apart.

Two of these configurations, one row and two rows close together, were also tested with waves approaching at an oblique angle (the main axis of alignment of the breakwater units at $24^{\circ}$ from the wave crests. The placement of the units in the two rows was staggered, or offset half the width of a unit.

For these tests, depth was varied to simulate tidal variations. Tests were conducted with model stillwater depths of $\mathrm{d}=18,23$, and $29 \mathrm{~cm}$. These depths correspond with $60 \%, 75 \%$, and $96 \%$ submergence of the full height of the structures.

Wave heights, defined as the difference in elevation of the crest and the trough of the wave, varied from $\mathrm{H}=5 \mathrm{~cm}$ to $\mathrm{H}=8.6 \mathrm{~cm}$ and two different wave periods, $\mathrm{T}=1.34 \mathrm{~s}$ and $\mathrm{T}=1.75 \mathrm{~s}$ were used. These periods correspond with prototype wave periods, using the Froude scaling relationship, of $\mathrm{T}=3 \mathrm{~s}$ and $\mathrm{T}=4 \mathrm{~s}$ which are typical of the fetch-limited, shallow-water, wind-generated seas at the Little Bay site. Wave heights in the laboratory were measured using two-wire, capacitance gages set at a sampling rate of $50 \mathrm{~Hz}$ and the signal was digitally recorded. The wave gages were calibrated statically at the beginning and end of the tests.

Wave transmission coefficient, $\mathrm{K}_{\mathrm{t}}$, is typically defined as the ratio of the transmitted wave height, $\mathrm{H}_{\mathrm{t}}$, (measured in the lee of the breakwater) to the incident wave height, $\mathrm{H}_{\mathrm{i}}$. For these tests, however, because of variations in wave height in the direction of wave propagation due to the nature of the motion of the bulkhead wave generator, an "influence coefficient" definition was adopted with wave height measured without any structure was used in place of the incident wave height (Takayama et al. 1985). Wave height was measured without any structure in the basin for the identical depth and wave generator motion.

These tests were run in "bursts" to avoid wave reflection contamination effects. Only the initial waves were included in the calculation of the transmission coefficients. These waves (not the first transient wave) included only those waves which reached the wave gage location prior to the time required for the first wave to reach the structure, reflect back to the bulkhead and then back to the gage location. For the limits of this basin and these wavelengths and speeds, this usually consisted of 2, 3, or 4 waves. A narrow sand beach slope was placed at the far end of the basin to reduce wave reflections in the basin. The burst length was established with wave speeds estimated using small-amplitude wave theory and confirmed by observation of reflections in the water surface elevation signal in the laboratory. The transmission coefficient data reported below were based on the average of these 2, 3 , or 4 wave heights in each "burst."

The wave transmission coefficients measured for the "Wave Attenuation Devices" ranged from $0.4<\mathrm{K}_{\mathrm{t}}<0.9$. The variation depended on emergence (depth), configuration, and wave period. Much of the variation was related to the configuration and some of the variation was due to the emergence (or depth). The implication of these results is that "Wave Attenuation Devices" may do a limited job of attenuating waves in some cases.

The results of the laboratory tests influenced the design of the Little Bay project breakwater several ways. First, the configuration of two rows of closely-spaced and staggered WADs were used to achieve the target wave height reduction through the breakwaters. Second, the WADs used in the design were increased in height to $1.8 \mathrm{~m}$ to obtain the target wave height reduction in the depths at Little Bay. Prior to the lab tests, a structure height of $1.4 \mathrm{~m}$ had been suggested as adequate (but this suggestion was not based on any quantitative analysis). 


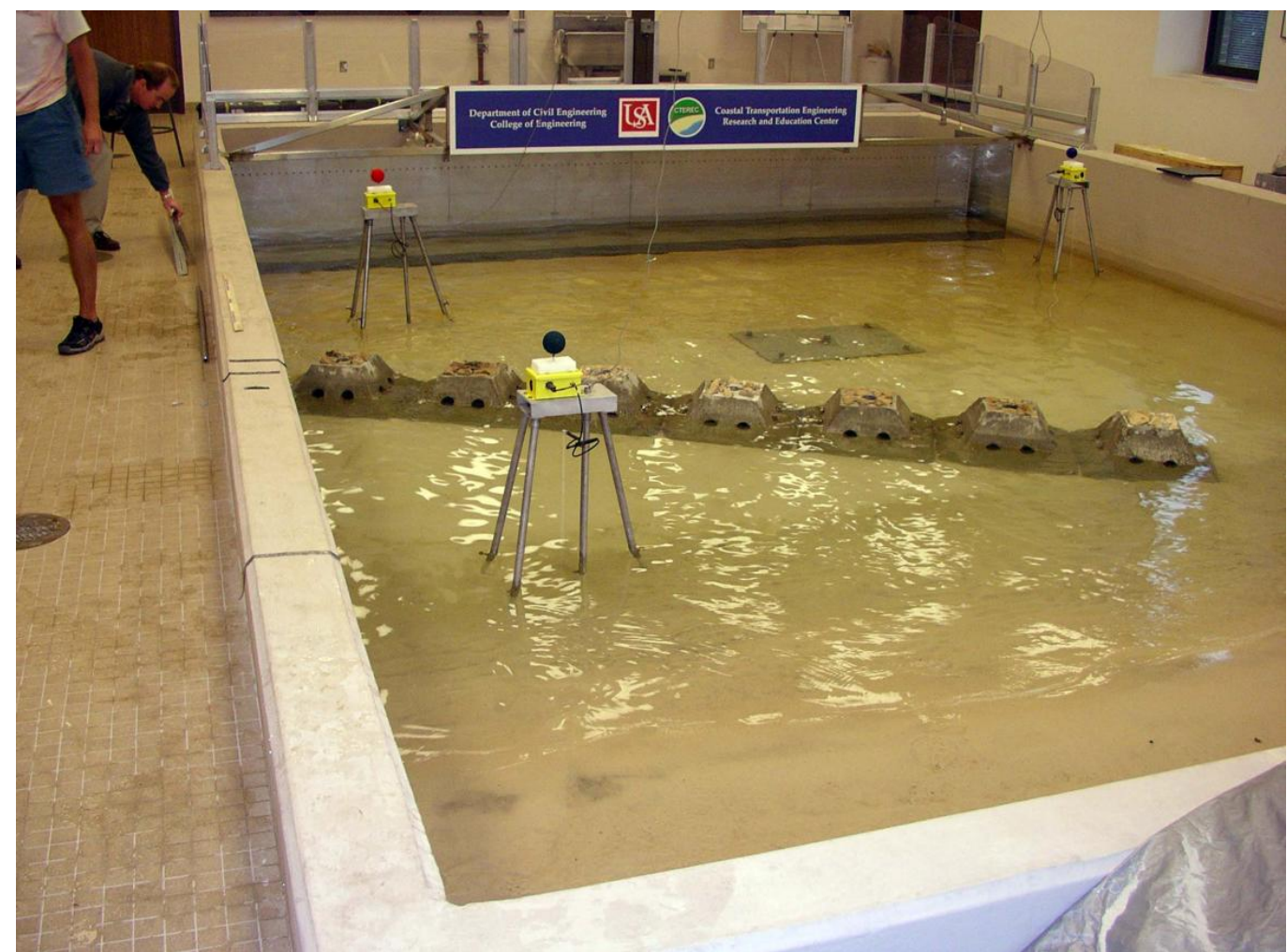

Figure 12. The University of South Alabama wave basin during 1:5 scale model wave transmission tests of of the so-called "Wave Attenuation Devices" or WADs eventually used in the Little Bay project breakwater. The test configuration shown is a single row of concrete units aligned obliquely to the incident waves.



Figure 13. A close-up photograph of the scale model concrete units called "Wave Attenuation Devices, or WADs," in the laboratory basin. 


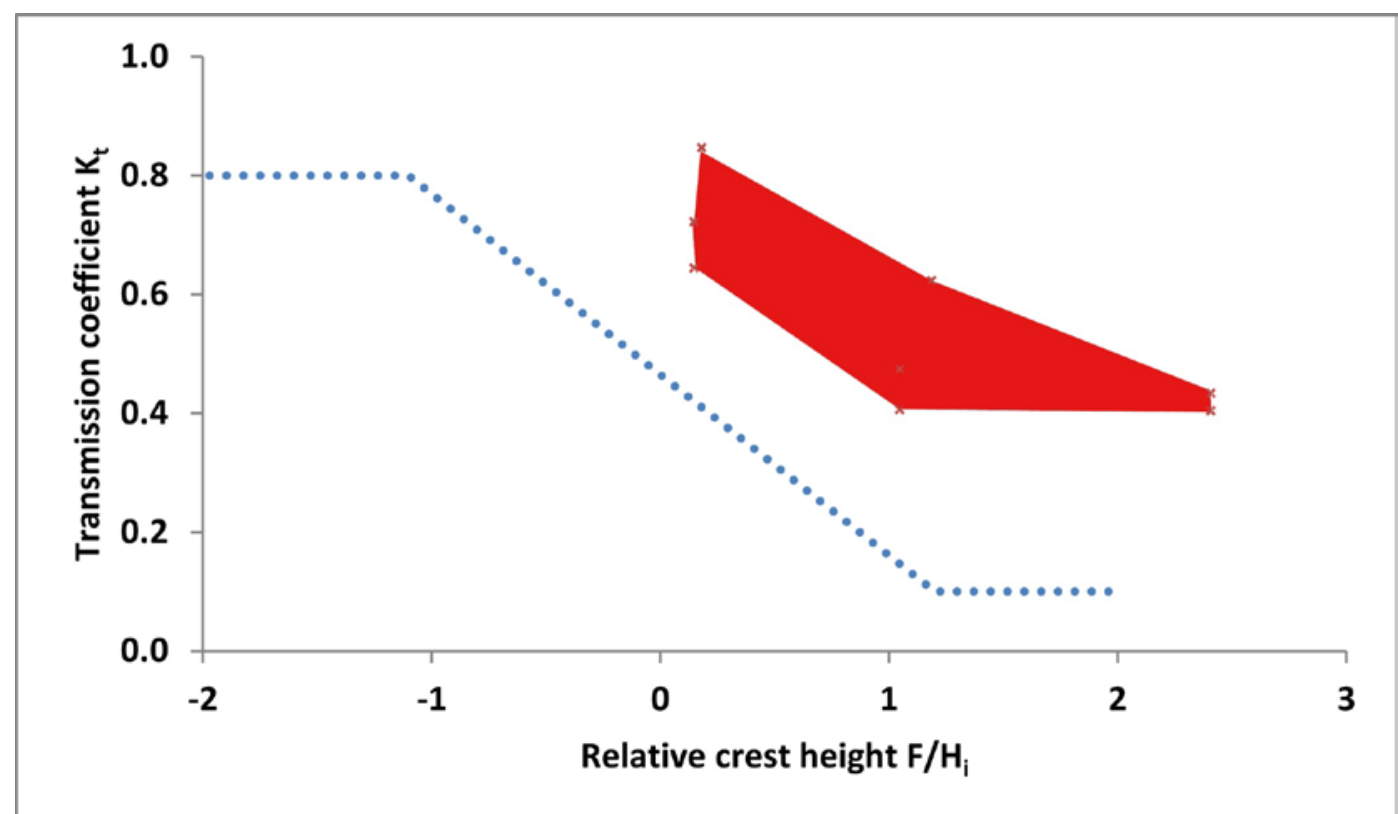

Figure 14. Laboratory test results for the wave transmission characteristics of breakwater consisting of "Wave Attenuation Devices," or WADs (red data envelope shown), compared with those of a traditional, stone rubble-mound breakwater (dashed blue line modified from Sorensen 2002)

The envelope of the laboratory WAD wave transmission test results is shown in Figure 14. Transmission coefficient, $K_{t}$, is plotted against relative crest height, $F / H_{i}$, defined as the ratio of the freeboard, $\mathrm{F}$, to the incident wave height, $\mathrm{H}_{\mathrm{i}}$. Freeboard, $\mathrm{F}$, is the vertical distance between the crest of the structure and the still-water-level. For emergent structures, relative crest height is greater than zero or positive and for submerged structures relative crest height is less than zero or a negative value. Also shown on Figure 14 is a line showing the equivalent transmission coefficient for more traditional stone, rubble-mound breakwater structures (modified from Sorensen 2002). The test results show how much more wave height is transmitted through the WAD breakwaters than rock breakwaters of the same height. These laboratory results indicate that there is 2 to 5 times the wave transmission through WAD breakwaters than through rock structures of equivalent heights. The wave transmission through the emerged WAD breakwater structures is roughly similar to the transmission through submerged rock structures. This fact indicates that some configurations of submerged structures can be used as an equivalent alternative to surface piercing WAD breakwaters. Further research into the wave transmission characteristics through WAD breakwaters is warranted because of the limited range of tests conducted here.

\section{LITTLE BAY PROJECT PERFORMANCE TO DATE}

The Little Bay project has performed very well to date both in terms of its physical performance and its ecological performance. Almost all of the sand remains in the project limits, all the native marsh in the lee of the project remains with no further erosion, the newly created habitat is a blend of growing vegetation, and there are oysters on the WADs. Figure 15 shows a typical photograph of the health of the newly planted vegetation in 2012 after about 15 months of growth. It is clear that a large fraction of the planted vegetation is thriving, growing, and expanding. Figure 16 shows egrets feeding on small fish in the project limits in 2011. Figure 17 shows a young crab hiding in the project in 2011. Overall, the project seems to have both created new marsh habitat with some significant ecological value as well as protecting the formerly eroding and degrading marsh to its north. The Dauphin Island Sea Lab is conducting extensive formal, long-term ecological monitoring of the Little Bay project and will begin to publish those results in the coming years. 


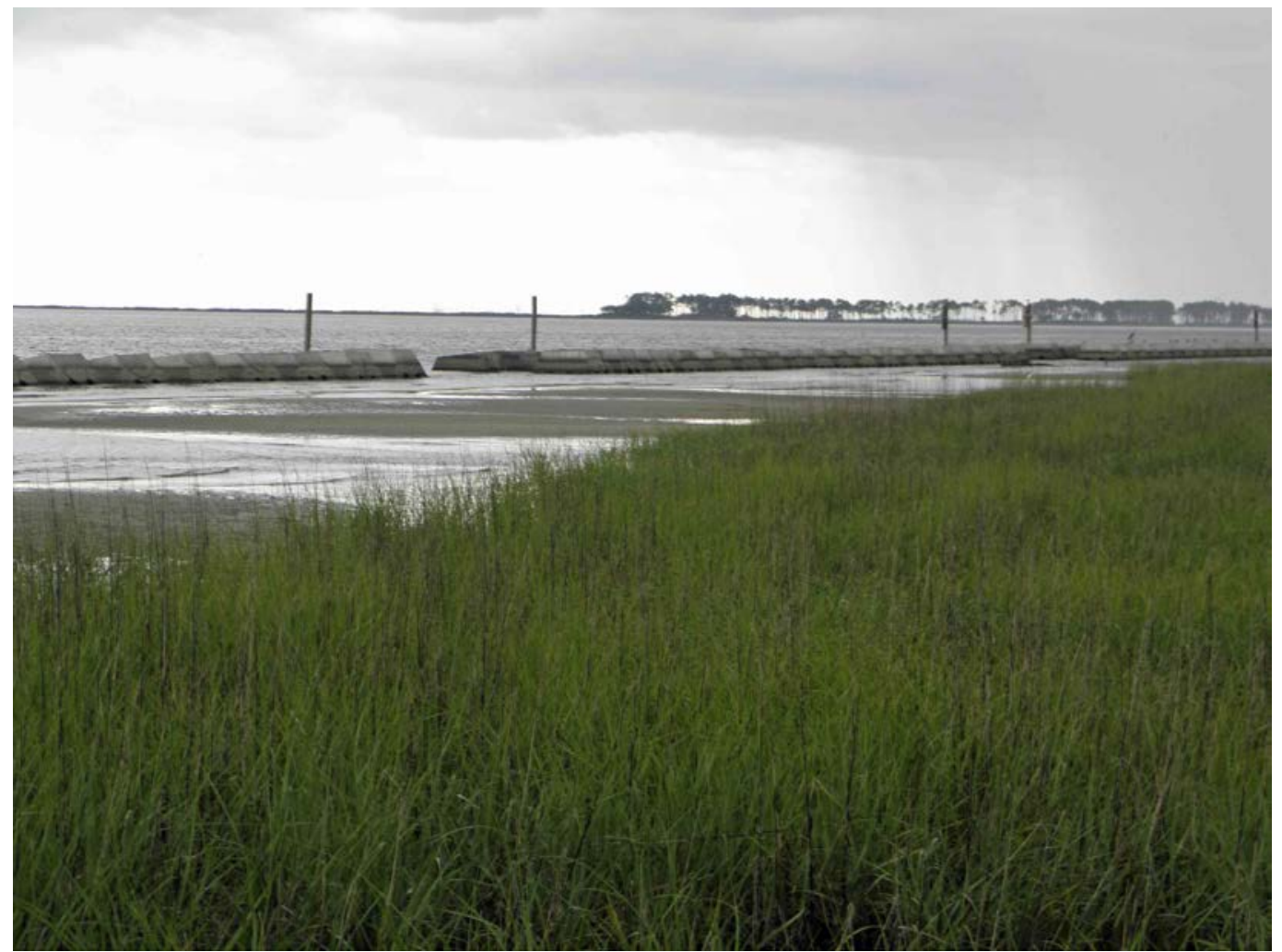

Figure 15. Vegetation in the Little Bay Project (Summer 2012).

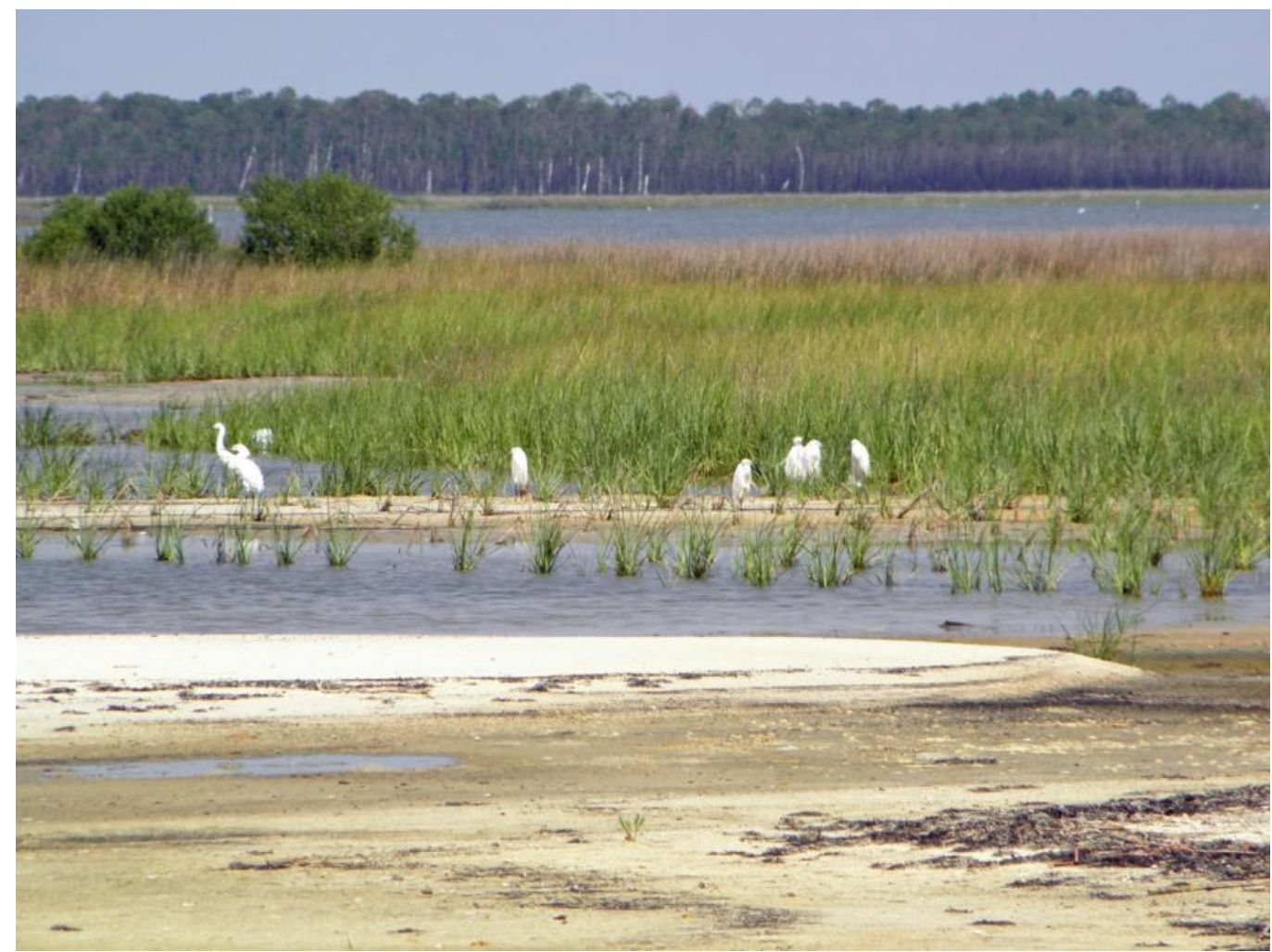

Figure 16. Egrets feeding on small fish in the Little Bay Project (Summer 2011) 


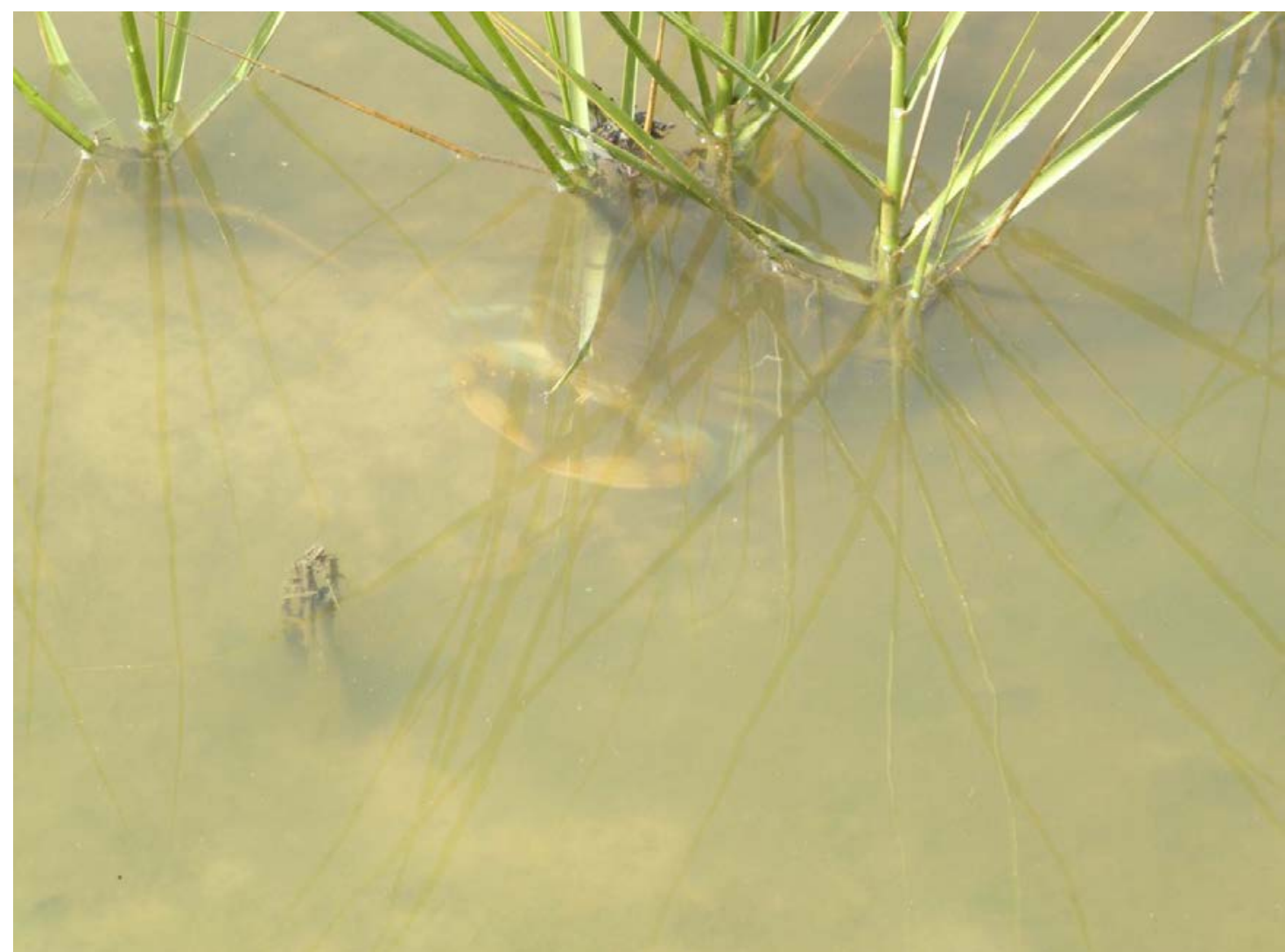

Figure 17. A small blue crab hiding in the shallows adjacent to some S. alterniflora vegetation in the Little Bay Project (summer 2011)



Figure 18. The Little Bay Finfish and Shellfish Marsh Restoration and Protection Project near Bayou LaBatre, Alabama, USA, immediately after passage of Tropical Storm Lee (photo date: September 2011) 
The Little Bay project likely experienced the design storm when Tropical Storm Lee subjected it to 72 hours of storm waves and surge in early September 2011. The tropical storm had a relatively small storm surge which allowed depth-limited waves to roll across the project for many hours. It is expected that larger storm surges, which will increase the depths over the marsh and structures much more, will have less of an impact because of those depths. By 2012, it was obvious that the WAD units are individually settling as expected with the seaward row showing more signs of scour and leaning out toward the sea.

The Little Bay project has won several state, regional and national design awards including:

- 2011 Engineering Excellence Award - Honorable Mention (American Council of Engineering Companies, ACEC)

- 2011 First Place Award of Excellence - Carl V. Anderson Conservation Project Award (Association of Conservation Engineers)

- 2011 Engineering Excellence Award - Grand Award (American Council of Engineering Companies of Alabama, ACEC-Alabama)

- 2010 Gulf Guardian Award - 3rd place - Business Category (EPA Gulf of Mexico Program)

- 2010 Project of the Year - Mobile Area Council of Engineers

The first award listed, the Engineering Excellence Award from the ACEC is called the "academy awards of engineering” and the overall winner in 2011 was the Hoover Dam bypass bridge. The success of the Little Bay project implies that the application of coastal engineering tools is valuable in the design of "living shorelines."

\section{ACKNOWLEDGEMENTS}

Funding for the Little Bay project was provided by NOAA Fisheries Emergency Disaster Relief Program (ERDP) Funds, Grant No. NA06NMF4540319, administered through the Alabama Department of Conservation and Natural Resources State Lands and Marine Resources Divisions.

A project this large involved dozens of professionals making decisions over a period of years that contributed to the project's overall success. They cannot all be named here but they know who they are and are thus acknowledged here. The overall design engineering firm for the Little Bay project was Volkert, Inc. of Mobile, Alabama. South Coast Engineers LLC Fairhope, Alabama provided coastal engineering services for this project which included the functional design of the breakwater configuration. Geotechnical Engineering \& Testing, Inc. of Mobile, Alabama provided geotechnical engineering services. Input from two colleagues at Volkert, Buddy Covington and Paul Looney, is gratefully acknowledged. Thomas J. "Beau” Buhring, University of South Alabama, contributed to this paper.

\section{REFERENCES}

Goda, Y. 2000. Random Seas and Design of Maritime Structures. Advanced Series on Ocean Engineering. World Scientific Press, vol. 15.

Roland, R. and S.L. Douglass. 2005. Estimating Wave Tolerance of Spartina alterniflora in Coastal Alabama, Journal of Coastal Research, vol. 21, no. 3, pp. 453-463.

Sorensen, R. 2002. Basic Coastal Engineering. Kluwer Academic Press.

Takayama T, K Nagai and T Sekiguchi. 1985. Irregular wave experiments on wave dissipation function of submerged breakwater with wide crown, Proceeding of 32th Japanese Conference on Coastal Engineering, JSCE, Vol.32, 545-549. 